NBER WORKING PAPER SERIES

\title{
UNDERSTANDING TRENDS IN ALTERNATIVE WORK ARRANGEMENTS IN THE UNITED STATES
}

Lawrence F. Katz

Alan B. Krueger

Working Paper 25425

http://www.nber.org/papers/w25425

\author{
NATIONAL BUREAU OF ECONOMIC RESEARCH \\ 1050 Massachusetts Avenue \\ Cambridge, MA 02138 \\ January 2019
}

This paper was presented at the Russell Sage Foundation Conference "Improving Employment and Earnings in Twenty-First Century Labor Markets", September 20-21, 2018, and is expected to be forthcoming in RSF: The Russell Sage Foundation Journal of the Social Sciences. We thank James Reeves for excellent research assistance and the conference participants and organizers for helpful comments. Ed Freeland provided assistance with our MTurk survey. Financial support from the Sloan Foundation is greatly appreciated. The views expressed herein are those of the authors and do not necessarily reflect the views of the National Bureau of Economic Research.

NBER working papers are circulated for discussion and comment purposes. They have not been peer-reviewed or been subject to the review by the NBER Board of Directors that accompanies official NBER publications.

(C) 2019 by Lawrence F. Katz and Alan B. Krueger. All rights reserved. Short sections of text, not to exceed two paragraphs, may be quoted without explicit permission provided that full credit, including $(\odot)$ notice, is given to the source. 
Understanding Trends in Alternative Work Arrangements in the United States

Lawrence F. Katz and Alan B. Krueger

NBER Working Paper No. 25425

January 2019

JEL No. J21, J81

\begin{abstract}
$\underline{\text { ABSTRACT }}$
This paper describes and tries to reconcile trends in alternative work arrangements in the United States using data from the Contingent Worker Survey supplements to the Current Population Survey (CPS) for 1995 to 2017, the 2015 RAND-Princeton Contingent Work Survey (CWS), and administrative tax data from the Internal Revenue Service for 2000 to 2016. We conclude that there likely has been a modest upward trend in the share of the U.S. workforce in alternative work arrangements during the 2000s based on the cyclically-adjusted comparisons of the CPS CWS's, measures using self-respondents in the CPS CWS, and measures of self-employment and 1099 workers from administrative tax data. We also present evidence from Amazon Mechanical Turk that suggests that the basic monthly CPS question on multiple job holding misses many instances of multiple job holding
\end{abstract}

Lawrence F. Katz

Department of Economics

Harvard University

Cambridge, MA 02138

and NBER

lkatz@harvard.edu

Alan B. Krueger

Industrial Relations Section

Louis A. Simpson International Bldg.

Room 261

Princeton University

Princeton, NJ 08544

and NBER

akrueger@princeton.edu 


\section{Introduction}

Many observers have speculated that traditional employment relationships may be in decline in the United States, driven by the rise of digital platforms and online gig work as well as through the increased fissuring of supply chains and use of domestic outsourcing leading to a greater use of contract workers and independent contractors (Weil 2014; General Accounting Office 2015). But high frequency, comprehensive, point-in-time measures of U.S. work arrangements have not been available (Bernhardt 2014).

In 2015, we attempted to fill this void. The U.S. Bureau of Labor Statistics (BLS) had been unable to conduct the Contingent Work Survey (CWS), a Current Population Survey (CPS) supplement and it main instrument for tracking alternative (or nonstandard) work arrangements, since 2005. We tried to update the CWS data by conducting the RAND-Princeton Contingent Work Survey (RPCWS), a version of the CWS, as part of the RAND American Life Panel in October and November 2015. At the time we undertook the RPCWS, the BLS did not have funding or plans to undertake another round of the CPS CWS in the near term. We attempted to make the RPCWS as comparable as possible the 2005 CPS CWS.

The 2015 RAND survey pointed to what appeared to be a substantial increase in the share of the workforce engaged in an alternative work arrangement on their main job compared with the 2005 CWS. Boosted by growth in the share of workers classified as self-employed freelancers or working for a contract firm that contracts workers out to work on-site at other companies, the percent of workers in alternative jobs rose from 10.7 percent in 2005 to 15.8 percent in 2015 (Katz and Krueger 2016, 2019). Online gig work appeared to account for only a small share of the large rise in alternative work arrangements through 2015. 
The increase in alternative work arrangements implied by the comparison of the 2005 CPS CWS and 2015 RPCWS seemed consistent as well with administrative tax data showing a rise in the share of tax returns and workers with self-employment income in the 2000s as seen in Schedule C filing rates and 1099 receipt rates (Abraham et al. 2018a,b; Jackson, Looney and Ramnath 2017; and Katz and Krueger 2016). Our study and related efforts using a range of sources (e.g., Abraham et al. 2018a,b and Farrell and Grieg 2016a,b) helped to generate a discussion of the incidence, composition, and nature of U.S. alternative work arrangements, and the need for more accurate and more frequent surveys and administrative data collection efforts.

Following our undertaking of the 2015 RPCWS, the BLS secured funding for a new CWS, which was conducted as a supplement to the May 2017 CPS. The 2017 CPS CWS findings were released in June 2018 and indicate, in seeming contrast to our earlier findings from the 2015 RPCWS, a slight decline in the incidence in alternative work arrangements from 10.7 percent in 2005 to 10.1 percent in 2017 (BLS 2018), driven by a decline in the share of workers classified as independent contractors.

In this paper, we revisit the measurement of trends in U.S. alternative work arrangements and try to reconcile our 2015 RPCWS results with the 2005 and 2017 CPS CWS findings. An analysis of all six CPS CWS's from 1995 to 2017 indicates a modest upward trend in the incidence of alternative work arrangements of about 1 percent of the workforce from 2000 to 2017, after accounting for business cycle conditions. The higher incidence of alternative work arrangements in the 2015 RPCWS than the CWS can largely be accounted for by cyclical conditions (a tighter labor market in 2017 than 2015), differences in survey methods (the use of self-responses only in the RPCWS vs. half the responses being from proxy respondents in the CPS CWS), and sampling issues with respect to the RAND web panel (an apparent oversample 
of multiple job holders in the RPCWS). After adjusting for these differences, the RPCWS suggests a 1-2 percentage point increase in the share of workers in alternative work from 2005 to 2015, instead of the 5 percentage point increase originally reported in Katz and Krueger (2016).

With the benefit of hindsight, we conclude that comparisons of trends in work arrangements across surveys with different sampling frames (as is the case for the CPS and RAND American Life Panel) and at different points of the business cycle require extra caution, even after the best attempts to the make surveys as comparable as possible. Another lesson is that workers appear to have a difficult time accurately reporting on their work status in standard surveys, and the problems are likely greater for proxy respondents (see, also, Abraham and Amaya 2018). We conclude that the basic monthly CPS and CWS instrument may have difficulty capturing changes in the incidence of casual or intermittent work in the United States because of respondent reporting errors that are likely to be exacerbated during a period of changing work relationships.

A puzzle remains concerning the rising trend in self-employment measures in administrative tax data compared to a declining trend in worker self-reports of self-employment rates in primary jobs in the CPS as seen in Figure 1. Schedule C filings as a share of CPS employment increased from 12.9 percent in 2000 to 16.6 percent in 2016 driven by a rise in the share of non-employers (Schedule $\mathrm{C}$ filers without any employees) as documented in Abraham et al. (2018a,b). In contrast, the share of employees in the CPS classified as self-employed, unincorporated continued a secular decline in the 2000s, falling from 7.5 percent in 2000 to 6.3 percent in 2016. We draw on an analysis of IRS administrative data from Collins et al. (2018) to explore in more detail the importance of online gig economy, primary vs. secondary jobs, and small jobs (low amounts of annual earnings) in accounting for the rise in the incidence of 1099 
receipts and self-employment income in the 2000s. The rise in the share of workers with 1099 receipts and self-employment incomes is driven by individuals with relatively small amounts of self-employment income where, over the course of a year, the earnings appear to be secondary and supplemental sources of income.

We also examine data on two new questions on "electronically mediated work" that were added to the 2017 CWS. The BLS concluded that more than two-thirds of affirmative responses to these new questions were false-positives, and recoded the data. In the recoded data, one percent of the workforce was classified as having performed electronically mediated work in the survey reference week, similar to our estimate from the RPCWS and to estimates by Farrell, Greig and Hamoudi (2018). Finally, we present evidence from Amazon Mechanical Turk that suggests that the basic monthly CPS question on multiple job holding misses many instances of multiple job holding.

\section{Reweighting the RAND Survey}

For our 2016 paper (Katz and Krueger 2016), we worked with the RAND Institute to add questions on alternative work arrangements to the RAND American Life Panel conducted in October and November 2015 resulting in the Rand-Princeton Contingent Worker Survey (RPCWS). The additional questions were closely patterned on the BLS's CWS questions. There are a number of important differences between the RPCWS and the CPS CWS, however. First, the RPCWS survey was conducted online, while the CWS is conducted in person or over the phone. Second, the RAND sample used in the RPCWS was recruited through a variety of means (e.g., a group recruited for the University of Michigan Internet panel, a random digit dial sample, and a snowball sample), and in all likelihood is less representative of the U.S. workforce than the 
CPS CWS sample. Third, all individuals self-respond about themselves in the RAND survey, while the BLS accepts proxy responses as well as self-responses in the CPS including the CWS. Approximately half of responses to the CPS CWS are from proxy respondents on behalf of others in their household. Fourth, the U.S. economy and the labor market were not as strong in October-November 2015 when the RPCWS was conducted as in May 2017 when the latest BLS CWS survey was conducted. Fifth, the sample size for the RPCWS survey is considerably smaller than the CPS. ${ }^{2}$

Did features of the RAND survey upwardly bias our estimate of the share of workers in alternative work arrangements compared with CWS? We first focus on the representativeness of the sample, and then turn to proxy respondents in the CPS and cyclical factors in the next section.

Table 1 reports the percent of workers engaged in various measures of alternative work arrangements from the RPCWS survey and all of the CWS surveys, for all respondents age 18 and older, and for three separate age groups (18 to 24,25 to 54 , and 55 to 75 years old). Panel A shows the percent of workers who report being self-employed on their main job based on the Basic Monthly CPS class of worker question, while Panel B shows the percent in alternative work categories based on CWS questions. "Independent Contractors" are individuals who report they obtain customers on their own to provide a product or service as an independent contractor, independent consultant, or freelance worker. "On-Call Workers" report having certain days or hours in which they are not at work but are on standby until called to work. "Temporary Help

\footnotetext{
${ }^{2}$ A sixth differences is that in some cases the skip logic in the RAND questionnaire slightly deviated from that used by BLS to compute statistics from the CWS, so we recomputed statistics from CWS to more closely mirror the RAND skip logic.
} 
Agency Workers" are paid by a temporary help agency. "Contract Workers" are individuals who worked for a company that contracted out their services during the reference week. ${ }^{3}$

Our figures do not exactly match the published CWS results because we use a different sample (age 18 and over) and because we use a different definition of contract workers to align with the RWCPS survey, but we were able to replicate the published CWS figures when we used the same sample restrictions and contract worker definition as BLS.

The raw (unweighted) 2015 RCPWS tabulations are shown in Column 1 of Table 1 indicating 13.3 percent of the work force in self-employment and 20.5 percent in alternative work arrangements. RAND developed a set of survey weights to adjust the ALP sample to more closely match the CPS based on age, gender, race/ethnicity, education and household income groups. These weights did not take into account self-employment or multiple job holding, however. The RAND sample contained a substantially higher percentage of workers who identified as self-employed than was the case in the CPS with 11.6 percent being self-employed in the RCPWS after applying the RAND weight as compared to 9.6 percent in the corresponding October 2015 CPS. Consequently, in our earlier paper we further adjusted the RAND weights to match the CPS self-employment rate in October 2015. Results using these weights, called "Altwt", are presented in Column 2 of Table 1. We took this step to protect against the possibility that the RAND sample may over represent workers who are more likely to be in alternative jobs.

\footnotetext{
${ }^{3}$ In the published CPS CWS tabulations, contract workers are further restricted to those "who are usually assigned to only one customer and usually work at the customer's worksite." We do not impose this restriction in our tabulations of the BLS CWS or RPCWS. Our results also differ from CWS because we restrict the CWS sample to those age and older who worked in the reference week to be comparable to RPCWS, whereas the official figures include those age 16 and older who were employed (but not necessarily worked) in the reference week.
} 
The estimates in Column 2 were the core focus of Katz and Krueger (2016) and implied 15.8 percent of the U.S. workforce was in alternative work arrangements in their primary job in October/November 2015. The implication was a large (5 percentage point) rise in the share working in alternative work arrangements from the 10.8 percent in the 2005 CWS (in Column 8) to the 15.8 percent in the 2015 RPCWS. In contrast, the May 2017 CWS in Column 9 yielded only 10.5 percent in alternative work arrangements.

Multiple job holding is another dimension in which the RAND sample does not match the CPS sample. In the unweighted RPCWS sample, 14.3 percent of workers reported multiple jobs, and in the weighted sample 13.1 percent reported multiple jobs. The corresponding figure from the October 2015 CPS is 5.2 percent. We did not previously adjust the RAND sample to match the CPS in terms of the proportion of workers who held multiple jobs, however. ${ }^{4}$ Because multiple job holders may be more likely to work in alternative jobs, we created a new set of weights ("Altwt 2") that adjusted the Altwt weights to down weight multiple job holders, and match the October 2015 CPS. Tabulations using these weights are reported in column 3 of Table 1. Using the second set of weights causes the share of workers in alternative jobs to fall by 2.1 percentage points (from 15.8 percent to 13.7 percent), and accounts for 40 percent of the 5.3 percentage point gap between the RPCWS survey and the 2017 CWS in terms of the overall share of workers in alternative work arrangements.

The largest discrepancy in the share of workers in alternative jobs between the RPCWS survey and the CWS (either 2005 or 2017) occurs for the oldest group of respondents (those 55 to 75 years old). Reweighting the RPCWS data to account for the oversampling of multiple job

\footnotetext{
${ }^{4}$ To partly address this discrepancy in our earlier paper (Katz and Krueger 2016), in one set of results we compared the share of contract workers who were single job holders. This narrowed the gap between the $2015 \mathrm{CWS}$ and the RPCWS sample by 1 percentage point.
} 
holders in the RAND survey shrinks the discrepancy for older workers, but it remains substantial (over 7 percentage points higher in the 2015 RPCWS than in the 2017 CWS) and much larger than for those 18 to 24 (a 0.5 percentage point gap) or those 25 to 54 (a 2 percentage point gap). A possible explanation for the age pattern in the discrepancy in the alternative work share in the RPCWS and the CWS is that internet panels, such as the RAND American Life Panel, may be particularly unrepresentative of older Americans. The RPCWS seems to especially oversample elderly individuals who report themselves to be independent contractors, with that category accounting for half of the discrepancy with the CWS. The higher incidence of temporary help agency and contract workers in the RPCWS is more similar for all three age groups.

\section{CWS: Cycle and Proxy Respondents}

The bottom row of Table 1 reports the seasonally adjusted unemployment rate in each month when the RAND and CWS surveys were conducted. The unemployment rate was 1.1 percentage point lower when the latest CWS was conducted in May 2017 than it was when the previous CWS was conducted in February 2005, and it was 0.7 percentage point lower in May 2017 compared with when the October -November 2015 RPCWS was conducted. If a tighter job market increases the fraction of workers who are in traditional employment, then cyclical factors could affect comparisons of the share of workers in alternative work over time.

The unemployment rate averaged 4.3 percent in February 1999 and February 2001, the same as it was in May 2017. Thus, a simple way to adjust for unemployment rate differences is to compare the average of the 1999 and 2001 CWS surveys to the 2017 CWS survey. The share of workers in alternative work arrangements rose by 1 percentage point from 1999-2001 to 2017, 
from 9.5 percent to 10.5 percent. A 0.6 percentage point increase in independent contractors was responsible for most of this rise.

Notice also that the unemployment rate was about the same when the CWS was conducted in 1997 and 2005, which provides another set of years to compare the growth in alternative work at similar points of the business cycle. Over this eight-year period, the share of workers in alternative jobs rose by 0.6 percentage point, again mainly because of a rise in independent contractors. These figures suggest that, cyclically adjusted, the share of independent contractors in the workforce is rising by 0.04 to 0.08 percentage point per year.

From 1997 to 1999, the unemployment rate fell by 0.8 percentage point and the CWS showed a 0.6 percentage point drop in the alternative work share. The decline in the unemployment rate between 2015 and 2017 was in the same ballpark, so the business cycle could perhaps account for 0.6 percentage point of the difference between the 2015 RPCWS and the 2017 CWS.

An alternative approach to examining trend vs. business cycle factors in alternative work arrangements is to use all six CPS CWS's from 1995 to 2017 shown in Columns 4 to 9 in Table 1. We regress the overall alternative work arrangements rate on the (seasonally adjusted) unemployment rate in the month of the survey and a linear (yearly) time trend yielding a coefficient (standard error) on the unemployment rate of $0.901(0.076)$ and on the trend of $0.0596(.0055) .^{5}$ The 0.7 percentage point gap in unemployment between October-November 2015 RWCWS and the May 2017 CWS multiplied by coefficient for unemployment also yields a 0.6 percentage point higher alternative work arrangements rate in the 2015 RWCPS than in the

\footnotetext{
${ }^{5}$ The analogous regression on the published BLS CWS share of all workers (16 and older) in alternative work arrangements leads to almost identical estimates of a $0.882(0.132)$ effect of unemployment and a $0.0525(0.0095)$ time trend coefficient.
} 
2017 CWS from a weaker labor market. The regression also implies a trend rise in the alternative work arrangements rate of 0.06 percentage point per year.

Independent contractor status in CWS is derived from different questions that were asked separately of the self-employed and wage and salary workers. Those who identify as selfemployed in the basically month class of worker question are asked: "Are you self-employed as an independent contractor, independent consultant, freelance worker, or something else?" And those who are classified as wage and salary workers in the basic monthly question are asked, "Last week, were you working as an independent contractor, an independent consultant or freelance worker? That is, someone who obtains customers on their own to provide a product or service." ${ }^{\prime 6}$ Following BLS, the results in Table 1 combine the two groups using the recoded data. From 1999-2001 to 2017, both groups contributed 0.3 percentage points to the overall rise in independent contractors.

One puzzle evident in the CPS data is that, although the cyclically adjusted share of independent contractors in CWS is rising slowly over time, the share of workers who report themselves as self-employed in the basically CPS is declining over the same time periods. The basic monthly CPS shows a particularly sharp decline in self-employment among older workers.

\section{Proxy Respondents}

Proxy respondents are likely to be less knowledgeable about the employment status of the person for whom they are reporting than the person him or herself, and possibly less willing to

\footnotetext{
${ }^{6}$ The RAND survey combined these two questions and asked it of everyone: "Last week, were you working or selfemployed as an independent contractor, an independent consultant, or a freelance worker? That is, someone who obtains customers on their own to provide a product or service." In the various years of the CWS, between 86 percent and 88 percent of the independent contractors were self-employed according the class of worker question.
} 
provide answers that lead to supplemental questions about alternative work arrangements as well. This could cause a "mode" bias where proxy respondents are more likely to report that a household member is employed in a traditional job than that household member would be had he or she been a self-respondent. Table 2 reports various statistics on proxy and self-respondents from the CWS. The share of responses in the CWS from proxy respondents has hovered close to 50 percent in all of the waves of the survey, while the RAND survey only accepts self-responses. The percent of responses from proxy respondents was 51.1 percent in 1995 and 48.9 percent in 2017. Katz and Krueger (2016) find that proxy respondents were about 2 percentage points less likely to report being in an alternative work arrangement than were self-respondents in the 1995 and 2015 CPS CWS surveys. Although it is not clear if the survey mode has a causal effect on responses, or if self-responders are truly more likely to be engaged in an alternative work arrangement (perhaps because they are likely to work from home, and therefore to be available to self-respond as self-employed when an interviewer visits their home or calls), the 2 percentage point differential persisted after we controlled for respondents' educational attainment, experience, race and sex in a linear probability regression model. Table 2 indicates that this gap has grown to 2.9 percentage points in 2017.

If the difference in the alternative work percentage is interpreted as a survey mode effect, then the fact that half of CPS respondents are proxy respondents could account for 1.5 percentage point of the difference between the 2015 RPCWS survey and the 2017 CWS.

Furthermore, the percentage of CWS self-respondents in alternative jobs shows a somewhat stronger upward trend over time than the corresponding percentage for proxy responses. The pattern is particularly apparent for independent contractors, where the share of independent contractors who are proxy respondents has fallen from 46.5 percent in 1995 to 41 
percent in 2017. The entire drop from 2005 to 2017 in the share of workers in alternative jobs occurred among proxy respondents in the CWS. The rate held steady for self-respondents.

\section{Summing $U p$}

We can account for just over 4 percentage points of the 5.3 percentage point difference in the 15.8 percent share of the work force in alternative work arrangements between the 2015 RPCWS reported in Katz and Krueger (2016) and the 10.5 percent in the 2017 CWS if 2.1 percentage points is a result of differential sample representativeness reflected in greater multiple jobholding in the RAND survey, 1.5 percentage point is due to the use of proxy respondents in CWS, and 0.6 percentage point is the result of differences in the state of the business cycle between 2015 and 2017.

\section{Trends in Administrative Tax Data}

Trends in self-employment have been diverging in survey and administrative tax data since 1980, with the contrast particularly striking in the 2000s as illustrated in Figure 1. Selfemployment based on worker self-reports in the CPS has declined in the 2000s, with the drop being driven by a decline in the unincorporated self-employed which fell 1.2 percentage points from 2000 to 2016. But the number of Schedule C filings as a share of employment has continued rising by 3.7 percentage points from 2000 to 2016. Abraham et al. (2018) also report a rise since 2000 in several administrative measures of self-employment for tax and census data, including the share of self-employed non-employer (individuals with more than $\$ 1,000$ in business income but no employees). And Abraham et al. (2018) find using linked household survey and administrative tax data for the same individuals that there is a noticeable increase in 
the share of individuals with self-employment income reported to the Internal Revenue Service (IRS) but not reported in the CPS. Jackson, Looney and Ramnath (2017) document that the share of the workforce with self-employment income (who are Schedule SE filers) increased from 10.1 percent in 2000 to 12.2 percent in 2014. Finally, Mishel (2018), using publicly-available Social Security Administration data, finds that the share of individuals with taxable earnings who have self-employment income increased from 9.6 percent in 2000 to 11.7 percent in 2015. The CWS and RPCWS data seem more consistent with the tax data in showing a modest rise in independent contractors as a share of employment in the 2000s (as seen in Table 1).

A potential reconciliation of the divergent trends in CPS and administrative tax measures of self-employment could be that the CPS measure covers only primary jobs but the tax measures include individuals with self-employment from secondary jobs or activities. But the tabulations in Mishel (2018) imply that the share of those with any taxable earnings who only had self-employment income increased by 1 percentage point, from 5.8 percent in 2000 to 6.8 percent in 2015 .

Collins et al. (2018) use micro administrative tax data from the IRS covering the universe of tax returns to attempt to reconcile the different trends in self-employment and alternative work arrangements and to explore the role of gig work mediated by online platforms. They report a substantial rise in the 1099 economy in the 2000s, with the share of the CPS workforce (those reporting any earnings over the course of the year in the March CPS) with 1099 income (from any 1099-MISC nonemployee compensation or from gig economy company income on a 1099K including non-tax filers typically with very low incomes), increasing from 12 percent in 2000 to 15.2 percent in 2016. A rising share of individuals receiving 1099 income from gig economy companies accounted for 1.2 percentage points (or about a third) of the increase. When 
restricting the sample to tax filers, they similarly report the share with any 1099 earnings increased from around 9 percent in 2001 to a little over 11 percent in 2016 with gig economy 1099s rising rapidly after 2013 and accounting for about half the increase.

Collins et al. (2018) explore in detail the patterns and distribution of 1099 and other selfemployment earnings in tax data. They find that the rise in the incidence of 1099 income is driven by individuals with 1099 income as secondary income and/or with low or modest levels of 1099 income (below $\$ 2500$ a year). The share of the work force earning a full-time, full-year income at the minimum wage ( $\$ 15,000$ or more) from 1099 income or self-employment (Schedule SE) income as their primary source of income has not noticeably risen since 2000.

Thus, assuming there has not been a rise in the under reporting of the amount of selfemployment income, the findings in Collins et al. (2018) suggest that self-employment as a primary income source has not been rising for workers with strong labor force attachment over the course of a year. These results are reinforced by Mishel's (2018) conclusion that much of the rise of the incidence of self-employment reflects side activities by freelancers as selfemployment earnings as a share of total earnings increased by much less than the share of workers with any self-employment income from 2000 to 2015.

\section{Measuring Multiple Job Holders}

As mentioned, the RAND survey indicates a much higher rate of multiple jobholding than the CPS. Since January 1994, the basically monthly CPS has asked respondents about multiple job holding. ${ }^{7}$ Multiple job holding is defined as working on more than one job during

\footnotetext{
${ }^{7}$ The key question is, "Last week, did (name/you) have more than one (job/job or business), including part time, evening or weekend work?"
} 
the survey reference week. BLS does not count individuals who were self-employed on their primary job and were either self-employed or an unpaid family worker on their second job as multiple job holders, which excludes workers who simultaneously work as independent contractors on Lyft and TaskRabbit, for example. Someone who reports moonlighting as a Lyft driver in addition to having a traditional W-2 job would be counted as a multiple job holder.

Despite the rise of the online platform economy, the monthly CPS shows a secular decline in multiple job holding. The percent of employees who were multiple job holders fell from an annual peak of 6.2 percent in 1996 to 4.9 percent in 2013. In the first half of $2018,5.0$ percent of workers were classified as multiple job holders. ${ }^{8}$ This decline has been cited as an indication that alternative work arrangements are not rising.

We designed a survey experiment using 2,291 participants age 18 and older recruited on Amazon Mechanical Turk (MTurk) to explore whether the standard CPS-type question on multiple job holding fails to capture a substantial amount of the secondary work that takes place. The survey was conducted online in late March 2015, and respondents were paid $\$ 3$ for their participation. Median survey completion time was 7 minutes. This sample was not chosen to be representative, but instead was selected to include a large number of workers who worked on multiple jobs, often on a casual basis. Our motivation was to determine whether relatively many multiple job holders neglect to report that they worked on multiple jobs based on the standard CPS question, and to probe whether multiple job holders could be identified if we asked more specifically about overlooked work activities in the previous week.

\footnotetext{
${ }^{8}$ Research has also found that multiple job holding rate is acyclic over time, and only weakly correlated with the unemployment rate across labor markets (see Hirsch, Husain and Winters, 2016).
} 
Specifically, along the lines of the CPS we asked, "Last week did you have more than one job or business, including part time, evening or weekend work?" A total of 39 percent of MTurk participants volunteered that that they had more than one job or business in the previous week.

After asking multiple job holders how many jobs they held in the previous week, we asked all respondents, "Did you work on any gigs, HITs or other small paid jobs last week that you did not include in your response to the previous question?" We next asked respondents to describe any work that they omitted.

Table 3 provides a tabulation of the responses. Of those who did not indicate holding multiple jobs on the CPS-like question, 61 percent acknowledged that they failed to report working on a gig, HIT or small job in the previous week. The omitted work was frequently tasks conducted on MTurk based on free-form descriptions, but also included work as writers, editors, teachers, dog sitters, and other freelance activities. If these workers are added to the multiple job holders, the percent of workers who are multiple job holders would almost double from 39 percent to 77 percent. $^{9}$

Younger respondents were much less likely to acknowledge omitting secondary jobs. Individuals with less than a college degree were also somewhat less likely to acknowledge omitting secondary jobs.

The MTurk sample is highly non-representative, but this survey experiment demonstrates that the standard multiple job holding question in the basic monthly CPS is susceptible to under-

\footnotetext{
${ }^{9}$ There may also be some false positives in the data: 9.8 percent of multiple job holders according to the CPS-type question reported that they held only one job in the previous week. Assuming that these answers are correct, the share of multiple job holders would be 72.6 percent, still indicating substantial under counting of multiple job holders.
} 
reporting. Abraham and Amaya (2018) similarly find in a survey experiment conducted with an MTurk sample in 2016 that additional probing identified a substantial amount of informal work activity not captured by the CPS employment questions, implying an understatement of the overall employment rate and the multiple job holding rate. Although it seems clear that the CPS fails to capture much secondary work activity leading to an understatement of the multiple job holding rate, the MTurk point in time surveys in 2015 and 2016 do not allow one to make assessments of whether there is a trend in the rate of understatement of multiple job holding.

Abraham and Amaya (2018) suggest that proxy respondents in the CPS may not be aware of multiple job holding arrangements for the worker on which they report. In the basic monthly CPS, we find that self-respondents are 25 to 40 percent more likely than proxy-respondents to report holding multiple jobs, depending on the month. It is unclear, however, whether this difference represents a proxy-respondent reporting effect, or a real difference in work behavior.

Table 3: Under Reporting of Multiple Jobs, Conditional on Self-Report Multiple Job Status

Failed to report gigs, hits or other small jobs last week

No

Yes

\section{Multiple job holder on CPS Question} No Yes

$38.6 \% \quad 61.6 \%$

61.4

38.4

Sample size is 2,291 participants on MTurk, March 30-31, 2016. See text.

\section{Electronically Mediated Work}

The May 2017 CWS included two new questions on electronically mediated work to measure participation in the platform economy. The questions were: 
Introduction I now have a few questions related to how the Internet and mobile apps have led to new types of work arrangements. I will ask first about tasks that are done in-person and then about tasks that are done entirely online.

Q1. Some people find short, IN-PERSON tasks or jobs through companies that connect them directly with customers using a website or mobile app. These companies also coordinate payment for the service through the app or website.

For example, using your own car to drive people from one place to another, delivering something, or doing someone's household tasks or errands.

Does this describe ANY work you did LAST WEEK?

- Yes

- No

Q2. Some people select short, ONLINE tasks or projects through companies that maintain lists that are accessed through an app or a website. These tasks are done entirely online and the companies coordinate payment for the work.

For example, data entry, translating text, web or software development, or graphic design.

Does this describe ANY work you did LAST WEEK?

- Yes

- No

In addition, in the case of affirmative responses to either question, a follow up question asked whether the work was for the respondent's main job, a second job, or other additional work.

About 3 percent of workers reported that they had performed some work in person or remotely (or both) through an online intermediary in the reference week. After an extensive review, however, the BLS “determined that these questions did not work as intended and had a 
large number of incorrect 'yes' answers." 10 BLS suspected a large number of affirmative responses were false positives, and recoded the originally reported responses to these questions using a confidential micro data file that included respondents' verbatim descriptions of their job duties, employer name, industry, occupation, and other information. (A handful of workers were reclassified in the opposite direction.) BLS has made both the original reports and the recoded data available, although all of the data that were used to recode the originally reported responses are not publically available. Using the BLS "as reported" and "reclassified" data, the false positive rate was 68.5 percent to question 1 (in-person tasks) and 76.4 percent to question 2 (remote tasks). Combining both questions, BLS recoded 69 percent of those who reported "yes" to at least one of the electronically mediated work as "no". ${ }^{11}$ Thus, in the recoded data, only 1 percent of the workforce is classified as working through an online intermediary.

Workers in some industries were much more likely to be reclassified as false positives than in others. For example, among those who originally reported themselves as finding some work through an online platform, 95 percent of workers whose primary industry was public administration, 94 percent of workers in manufacturing, and 91 percent of workers in construction were reclassified as not working online. By contrast, only 33 percent of workers in transportation and warehousing were reclassified as false positives.

The apparently high rate of false positive classification errors, even in the transportation industry, where Uber, Lyft, and other ride sharing platforms are used by a substantial proportion

\footnotetext{
${ }^{10}$ See Current Population Survey staff, "Electronically mediated work: new questions in the Contingent Worker Supplement," Monthly Labor Review, U.S. Bureau of Labor Statistics, September 2018, https://doi.org/10.21916/mlr.2018.24.

${ }^{11}$ Proxy respondents were only slightly more likely than self-respondents to be reclassified as false positives (70.0 percent versus 68.2 percent).
} 
of workers, is indicative of the difficulty inherent in assessing the percentage of the workforce in alternative work arrangements from household survey data. Nonetheless, similar to the BLS's recoded CWS data, Katz and Krueger (2016, 2019) and Farrell, Greig and Hamoudi (2018) estimate that only 0.5 percent to 1.5 percent of the workforce was engaged in online work for sample periods covering late 2015 to the end of 2017.

\section{Conclusions}

We conclude that there likely has been a modest upward trend in the share of the U.S. workforce in alternative work arrangements during the 2000s based on the cyclically-adjusted comparisons of the CPS CWS's, measures using self-respondents in the CPS CWS, and measures of self-employment and 1099 workers from administrative tax data. The growth in alternative work arrangements is not as sharp as suggested by Katz and Krueger's (2016) comparison of the 2015 RPCWS and the 2005 CPS CWS if more consistent measures are compared over time. Differences in survey methods between the CPS CWS and the RPCWS related to the use of proxy respondents in the CPS and the less representative nature of the RAND American Life Panel than the CPS likely account for an overstatement in trend growth in alternative work arrangements in Katz and Krueger (2016).

Estimating the percentage of workers in alternative work is a difficult task in household surveys. Since only a relatively small proportion of workers are currently working in alternative employment in any given week, and often for relatively modest amounts of income or short periods of time, respondent (or coder) misclassifications and other non-sampling errors are likely to exert a sizable impact on estimates. In view of the differential trends in the CWS between proxy and self-respondents, one suggestion from our analysis is that BLS should consider only 
using self-responses for CWS because proxy respondents may not be knowledgeable. In addition, given the difficulty of measuring alternative work in household surveys, it might also be worthwhile for BLS to probe more deeply involvement in secondary work, as in our MTurk experiment. Abraham and Amaya (2018) suggest that much casual work is not reported in CPS. The ancillary information in the verbatim descriptions of job duties, employer name, and industry were useful in recoding a large number of presumed false positives in the BLS's new electronical medicated employment questions, and a more deliberate approach to probing about nonstandard work activities and secondary jobs could also be informative.

When it comes to measuring trends over time, an important lesson from our review of the evidence is that it is essential to hold constant survey modes, questionnaires, and survey design features to guard against the risk that non-sampling errors dominate time-series comparisons. A similar lesson was clear from the 1992-93 CPS parallel overlap sample, which was used to evaluate the effects of the 1994 CPS Redesign on employment, labor force and unemployment (see Polivka and Miller, 1998). Although the fraction of workers employed in alternative work could be biased in any given year, repeated measures could nonetheless reflect actual changes over time if survey methods are held constant. In this regard, it could be a useful exercise to conduct another wave of the RPCWS survey in the future to assess trends in alternative work. 


\section{References}

Abraham, Katharine G. and Ashely Amaya. "Probing for Informal Work Activity," NBER WP No. 24880, August 2018.

Abraham, Kathrine G., John C. Haltiwanger, Kristin Sandusky, and James R. Spletzer. "Measuring the 'Gig' Economy: Current Knowledge and Open Issues," NBER WP No. 24950, August 2018b.

Abraham, Kathrine G., John C. Haltiwanger, Kristin Sandusky, and James R. Spletzer. "Driving the Gig Economy," July 2018a; http://papers.nber.org/conf_papers/f110357/f110357.pdf.

Bernhardt, Annette. "Labor Standards and the Reorganization of Work: Gaps in Data and Research," UC Berkeley, Institute for Research on Labor and Employment, January 2014; http://www.irle.berkeley.edu/workingpapers/100-14.pdf.

Collins, Brett, Andrew Garin, Emile Jackson, Dmitri Koustas, and Mark Payne. "Understanding the Trend in U.S. Alternative Work Arrangements: Evidence from Tax Data," October 2018.

Farrell, Diana and Fiona Greig; "Paychecks, Paydays and the Online Platform Economy," JPMorgan Chase \& Co. Institute, February 2016a; https://www.jpmorganchase.com/corporate/institute/research.htm.

Farrell, Diana and Fiona Greig. "The Online Platform Economy: Has Growth Peaked?" November 2016b; https://www.jpmorganchase.com/corporate/institute/research.htm.

Farrell, Diana, Fiona Greig, and Amar Hamoudi. "The Online Platform Economy in 2018: Drivers, Workers, Sellers and Lessors," September 2018; https://www.jpmorganchase.com/corporate/news/pr/institute-2018-online-platformeconomy-report-findings.htm

General Accounting Office, "Contingent Workforce: Size, Characteristics, Earnings, and Benefits," GAO-15-168R, April 2015, available from: http://www.gao.gov/products/GAO15-168R.

Hirsch, Barry T., Muhammad M. Husain, and John V. Winters. "Multiple job holding, local labor markets, and the business cycle." IZA Journal of Labor Economics 5, no. 1 (2016): 4.

Jackson, Emilie, Adam Looney, and Shanthi Ramnath, "The Rise of Alternative Work Arrangements: Evidence and Implications for Tax Filing and Benefit Coverage," Office of Tax Analysis Working Paper No. 114, U.S. Department of the Treasury, Washington, D.C., January 2017. 
Katz, Lawrence F. and Alan B. Krueger, "The Rise and Nature of Alternative Work Arrangements in the United States, 1995-2015," NBER Working Paper No. 22667, September 2016.

Katz, Lawrence F. and Alan B. Krueger, "The Rise and Nature of Alternative Work Arrangements in the United States, 1995-2015." ILR Review, forthcoming 2019.

Mishel, Lawrence. "Social Security Data Confirm Same Old Patterns: Self-employment Headcount Has Risen but Economic Impact Remains Small," Economic Policy Institute Working Economics Blog, June 28, 2018; https://www.epi.org/blog/social-security-dataconfirm-same-old-pattern-self-employment-headcount-has-risen-but-economic-impactremains-small $/$.

Polivka, Anne E., and Stephen M. Miller. "The CPS after the redesign: Refocusing the economic lens." In John Haltiwanger, Marilyn E. Manser, and Robert Topel, eds., Labor Statistics Measurement Issues, pp. 249-289. University of Chicago Press and NBER, 1998.

U.S. Bureau of Labor Statistics. "Contingent and Alternative Arrangements - May 2017," USDL-18-0942, June 2018; https://www.bls.gov/news.release/pdf/conemp.pdf.

Weil, David, The Fissured Workplace, Cambridge, MA: Harvard University Press, 2014. 
Figure 1: Trends in Self-Employment

Percent of CPS Total Employed

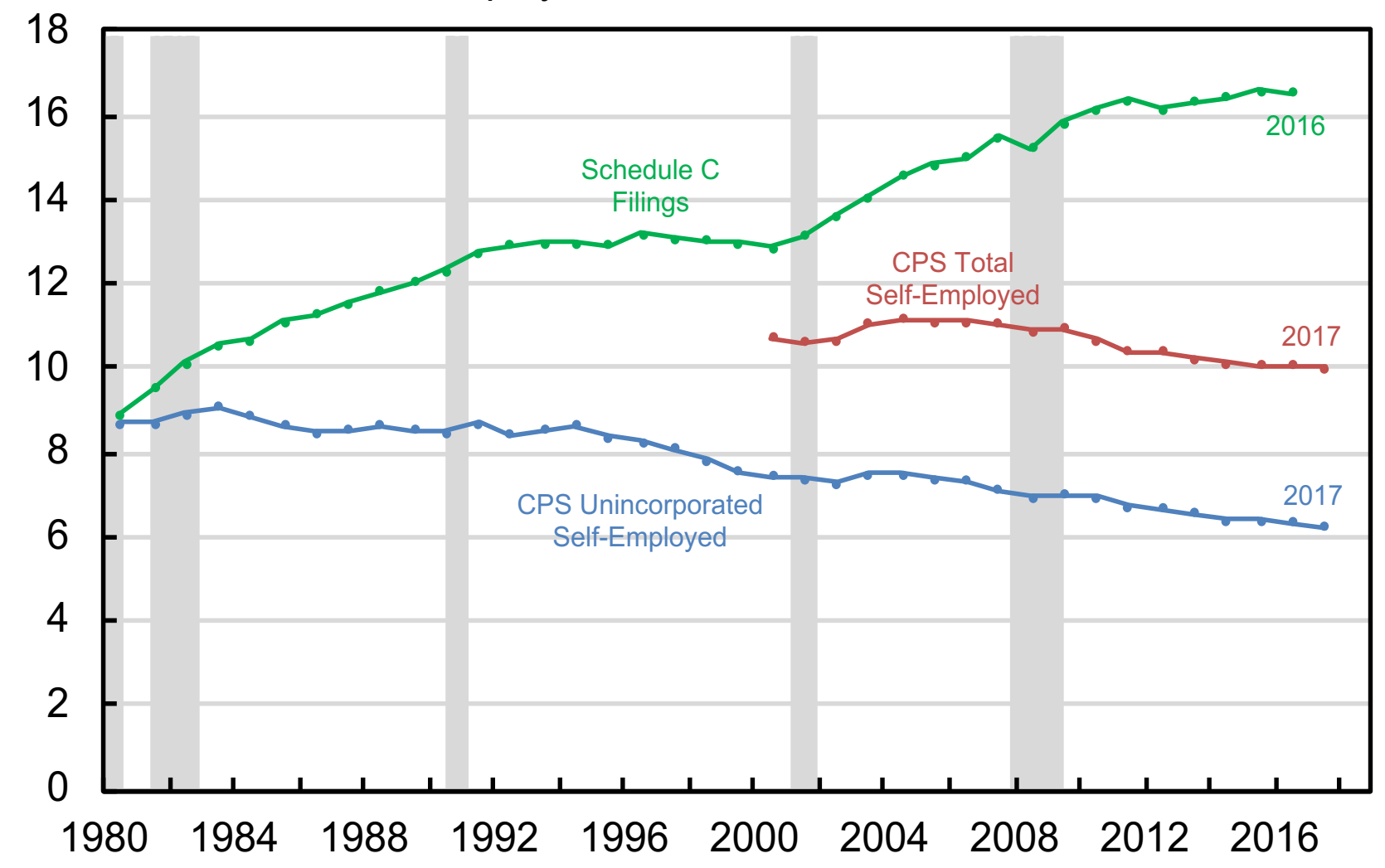

Sources: Self-employment measures from Current Population Survey and Schedule C Filings from IRS Statistics of Income Publication 1304, Table 1.3. 
Table 1: Self-Employed and Alternative Work Arrangements

\begin{tabular}{|c|c|c|c|c|c|c|c|c|c|}
\hline & $\begin{array}{c}\text { Rand } \\
\text { Unwt. }\end{array}$ & $\begin{array}{l}\text { Rand } \\
\text { Altwt }\end{array}$ & $\begin{array}{c}\text { Rand } \\
\text { Altwt } 2\end{array}$ & $\begin{array}{l}1995 \\
\text { CWS } \\
\end{array}$ & $\begin{array}{l}1997 \\
\text { CWS } \\
\end{array}$ & $\begin{array}{l}1999 \\
\text { CWS } \\
\end{array}$ & $\begin{array}{l}2001 \\
\text { CWS } \\
\end{array}$ & $\begin{array}{l}2005 \\
\text { CWS } \\
\end{array}$ & $\begin{array}{l}2017 \\
\text { CWS } \\
\end{array}$ \\
\hline Panel A: Self-Employed (Basic Monthly) & $(1)$ & $(2)$ & (3) & (4) & $(5)$ & $(6)$ & $(7)$ & $(8)$ & $(9)$ \\
\hline Overall & 13.3 & 9.6 & 9.2 & 11.6 & 11.3 & 10.6 & 10.2 & 10.8 & 9.9 \\
\hline $18-24$ & 5.1 & 5.9 & 6.5 & 2.7 & 2.4 & 2.2 & 1.8 & 2.0 & 2.3 \\
\hline $25-54$ & 9.2 & 7.3 & 6.9 & 11.8 & 11.2 & 10.5 & 10.3 & 10.6 & 9.1 \\
\hline $55-75$ & 19.9 & 18.1 & 17.0 & 20.2 & 20.2 & 18.9 & 17.8 & 18.0 & 15.7 \\
\hline \multicolumn{10}{|l|}{ Panel B: Alternative Work Arrangements } \\
\hline Any Alternative Work Arrangement & 20.5 & 15.8 & 13.7 & 10.1 & 10.2 & 9.6 & 9.4 & 10.8 & 10.5 \\
\hline $18-24$ & 8.5 & 6.4 & 5.7 & 6.7 & 6.6 & 6.5 & 6.5 & 7.4 & 6.2 \\
\hline $25-54$ & 17.1 & 14.3 & 11.9 & 10.0 & 10.1 & 9.5 & 9.2 & 10.4 & 9.9 \\
\hline $55-75$ & 26.5 & 23.9 & 21.5 & 14.1 & 14.1 & 13.3 & 13.6 & 15.1 & 14.4 \\
\hline Independent Contractors & 11.7 & 8.4 & 7.2 & 6.4 & 6.4 & 6.1 & 6.1 & 7.0 & 6.7 \\
\hline $18-24$ & 3.4 & 2.1 & 2.4 & 1.5 & 1.5 & 1.6 & 1.7 & 2.2 & 2.1 \\
\hline $25-54$ & 8.1 & 6.8 & 5.5 & 6.6 & 6.5 & 6.2 & 6.1 & 6.8 & 6.2 \\
\hline $55-75$ & 17.8 & 15.8 & 13.8 & 10.5 & 10.4 & 9.7 & 10.5 & 11.3 & 10.4 \\
\hline On-Call Workers & 2.6 & 2.6 & 2.4 & 1.5 & 1.5 & 1.5 & 1.5 & 1.7 & 1.6 \\
\hline $18-24$ & 0.0 & 0.0 & 0.0 & 1.9 & 2.1 & 1.7 & 2.4 & 2.4 & 1.8 \\
\hline $25-54$ & 2.3 & 2.6 & 2.3 & 1.4 & 1.3 & 1.3 & 1.3 & 1.5 & 1.5 \\
\hline $55-75$ & 3.1 & 3.3 & 3.2 & 2.2 & 2.0 & 2.1 & 1.6 & 1.9 & 1.9 \\
\hline Temporary Help Agency Workers & 2.0 & 1.6 & 1.7 & 1.0 & 1.0 & 0.9 & 0.9 & 0.9 & 0.9 \\
\hline $18-24$ & 1.7 & 1.7 & 1.9 & 1.8 & 1.8 & 1.9 & 1.5 & 1.4 & 1.3 \\
\hline $25-54$ & 2.3 & 1.6 & 1.6 & 0.9 & 0.9 & 0.8 & 0.8 & 0.8 & 0.9 \\
\hline $55-75$ & 1.5 & 1.7 & 1.7 & 0.6 & 0.8 & 0.7 & 0.9 & 0.7 & 0.8 \\
\hline Contract Workers & 4.2 & 3.1 & 2.5 & 1.3 & 1.4 & 1.3 & 1.1 & 1.4 & 1.4 \\
\hline $18-24$ & 3.4 & 2.5 & 1.4 & 1.5 & 1.3 & 1.5 & 1.1 & 1.5 & 1.1 \\
\hline $25-54$ & 4.4 & 3.2 & 2.4 & 1.4 & 1.5 & 1.4 & 1.1 & 1.4 & 1.5 \\
\hline $55-75$ & 4.1 & 3.1 & 2.8 & 1.0 & 1.0 & 0.9 & 0.7 & 1.4 & 1.4 \\
\hline Observations & 2,194 & 2,194 & 2,194 & 54,415 & 53,493 & 49,420 & 36,574 & 42,087 & 46,071 \\
\hline
\end{tabular}




\section{Unemployment Rate (SA)}

5.0

5.0

5.4

5.2

4.4

4.2

5.4

the percent who are in alternative work arrangements. The sample contains employed workers who are aged 18 or more. Panel A reports the percent of employed workers who are self-employed. Panel B reports the percent of employed who are independent contractors, on-call workers, temporary help agency workers, and contract workers. Any alternative work arrangement includes all of the listed categories in panel B.

Individual categories may not add to the total due to rounding or changes in definitions that improve comparability between the RPCWS and CPS CWS. Column 1 reports unweighted figures from the 2015 RPCWS, column 2 reports figures using a set of weights that accounts for the overrepresentation of self-employed workers, and column 3 reports figures using a set of weights that further accounts for the overrepresentation of multiple job holders in the American Life Panel, both relative to the October 2015

Current Population Survey. Columns 4-9 are from the 1995, 1997, 1999, 2001, 2005, and 2017 Contingent Worker Survey Supplements and are weighted using final weights in panel A and supplement weights in panel B. 
Table 2: Proxy Respondents and Alternative Work Arrangements

\begin{tabular}{lccccc}
\hline & \multicolumn{2}{c}{ Proxy Respondents } & & \multicolumn{2}{c}{ Alt. Work Arr. } \\
\cline { 2 - 3 } \cline { 5 - 6 } & $\begin{array}{c}\text { All } \\
\text { Respondents }\end{array}$ & $\begin{array}{c}\text { Independent } \\
\text { Contractors }\end{array}$ & & $\begin{array}{c}\text { Self- } \\
\text { Respondents }\end{array}$ & $\begin{array}{c}\text { Proxy } \\
\text { Respondents }\end{array}$ \\
\cline { 2 - 3 } & $(1)$ & $(2)$ & & $(3)$ & $(4)$ \\
1995 & 51.1 & 46.5 & & 10.9 & 9.2 \\
1997 & 50.6 & 43.9 & & 11.2 & 9.0 \\
1999 & 50.8 & 44.9 & & 10.6 & 8.5 \\
2001 & 50.8 & 44.0 & & 10.4 & 8.3 \\
2005 & 50.1 & 43.9 & & 11.8 & 9.6 \\
2017 & 48.9 & 41.0 & & 11.8 & 8.9 \\
\hline
\end{tabular}

Note: This table reports the percent of respondents in the CWS who were proxy respondents and the percent of respondents who were in alternative work arrangements. Column 1 reports the percent of CWS respondents who were proxy respondents and column 2 reports the percent of independent contractors who were proxy respondents. Columns 3 and 4 report the percent of self-respondents and proxy respondents, respectively, who reported being in an alternative work arrangement. All columns are weighted using supplement weights. 